\title{
Modeling for Minimization of Loneliness of People on the Social Networking Websites
}

\section{Taskeen Zaidi* and Vipin Saxena}

Department of Computer Science, Babasaheb Bhimrao Ambedkar University, Lucknow, India

\begin{abstract}
In the current scenario of human life, use of Internet is an integral part of human being. Internet users are rapidly increasing worldwide. Use of internet is directly or indirectly affecting the life of human being as there are several advantages and disadvantages for using the services of internet especially for the online shopping, reading, searching articles, watching movies, net surfing, etc. In the present work, a real case study of domain of Indian people is considered and questionnaire for Internet Addiction Test is prepared and statistical analysis is used to find out some of important observations related to human being which are using the internet services. Although in India, rate of internet users is very poor however Internet Addiction Test shows some significant results which minimize the loneliness of human being due to vast use of social networking sites. A model is also proposed by the use of most popular object-oriented modeling platform independent language known as the Unified Modeling Language. One can easily develop the software code through proposed model by the use of any object-oriented programming language. Systematic steps are represented through model for minimization of loneliness of people which is converted into happiness by the use of the social networking websites. The proposed model is also validated by generation of valid test cases through Finite State Machine.
\end{abstract}

Keywords: Technology; Internet; Statistical techniquest

\section{Introduction}

In India, the fastest growing network is the internet. Recently an application of social networking websites namely WhatsApp is gaining popularity in India. These types of applications are minimizing the loneliness of the people. From the literature, it is seen that various authors from different countries have studied the loneliness of the people by drafting a sample questionnaire related to the internet users. Since India is a poor country; $24 \%$ of population is below the poverty line, $30 \%$ population is middle class population, literacy rate is around $75 \%$ of population but only $25 \%$ people are the internet users out of 1.27 billion people therefore it is observed that people feel more lonely due to non availability of the entertainment resources like television, mobile device, laptop, etc. Many of the state government have launched a project for distribution of the laptop's to the higher studies students alongwith wi-fi internet facilities. But in the recent year 2015 and expansion of technology in India loneliness of the people is minimizing due to sudden increment in the internet users. It can be seen on the road that owner of cycle rickshaw is also using the mobile device which is well connected across the network.

The present work is a motivation in this direction to study the status of loneliness of the people in Indian context. An object-oriented platform independent Unified Modeling language is selected to develop a model for conversion of loneliness of the people into the happiness. The presented model can be easily converted by the software programmer through any object-oriented programming language. It is also seen that there is no software tool available in the literature for observing the various parameters related to the minimization of the loneliness of people. The model is further validated through Finite State Machine (FSM) by generation of valid test cases. Statistical techniques are also used for validation of the model and for observing the behavior of the various dependent variables occurring in the model. A survey on five hundred people is performed with an average age of twenty three years $(\mathrm{SD}=1.53)$ with three hundred females and two hundred males. The real data is collected after taking the ethical consent of people from location of different Universities available in Lucknow city of India and observed some significant results for people happiness.

\section{Related Work}

Due to evolution of distributed computing system, world wide web (www) is the fastest growing network across the globe. A distributed system is an autonomous collection of various kinds of hand-held devices like mobile, palmtop, laptop, etc. Web applications are based upon the approach of distributed computing network [1,2]. Internet services play a vital role in the social life of human being [3]. Past research has proved that people are enjoying the internet services in both the aspects either positively or negatively [4,5]. When people are using social networking websites like www.facebook.com, www. classmates.com, etc then negative aspects of use of internet services are occurred [6]. It is also seen from past research that internet services can be used very effectively to enhance quantity and quality of friendships which have positive impact on human being of internet users $[7,8]$. Different case studies are produced by various researchers according to locations and observed that there is vast use of social networking websites in South Korea for well-being and self-satisfaction of the people $[9,10]$.

Social networking websites represent technological features and social connections among the people and most popular website is www.facebook.com which has extensive impacts of happiness among

*Corresponding author: Taskeen Zaidi, Department of Computer Science Babasaheb Bhimrao Ambedkar University, Lucknow, India, Tel: 009452372550; E-mail: taskeenzaidi867@gmail.com

Received January 27, 2015; Accepted February 26, 2015; Published March 05 2015

Citation: Zaidi T, Saxena V (2015) Modeling for Minimization of Loneliness of People on the Social Networking Websites. J Psychiatry 18: 257 doi: 10.4172/psychiatry. 1000257

Copyright: ( 2015 Zaidi T, et al. This is an open-access article distributed under the terms of the Creative Commons Attribution License, which permits unrestricted use, distribution, and reproduction in any medium, provided the original author and source are credited 
the people connected across distributed network [11]. A study of undergraduate students is available in the literature for using the www. facebook.com website which reduces the loneliness and enhance the emotional satisfaction, increasing one's well-being, etc. [12]. Some of the researchers have suggested that the loneliness has negative effect on the human being due to loneliness, depression. Computer self-efficiencies are the predictors of problematic internet use and it is directly related to the physiological well-being $[13,14]$. Russell has scaled the loneliness according to reliability, validity and factors the structure according to seven point scale [15].

Some of authors have also observed that social communication skill is very poor in the lonely people and some time they became negative due to internet addiction [16]. In the current scenario, people are registering online for the purchase of items and enjoying the positive and negative aspects of online shopping [17]. Use of internet is directly proportional to the psychological health and there are social resources on the changes in depression which leads to the psychological health [18]. Due to lots of access of social networking websites, there are tremendous amount of data with less security for the social communications on cyberspace and these data are not filtered for the employers' use [19].

Orchard and Fullwood observed the behavior of the users who often use the internet and also compared with offline users [20]. It is found that many of the employers check out applicants through social networking websites [21]. Barrick and Mount explained the five dimensions for five personalities related to the job performance. They indicated that conscientiousness has also been called "conformity", "dependability" and finally "will to achieve" the goal. It is defined with variety of adjectives like careful, thorough, responsible, organized, self disciplined and hardworking [22]. Previous studies have also indicated that young adults are doing lots of activities on the internet and they treated as a passion to enhance their personality, true self, etc [23]. Facebook profiles are more popular and daily the size of database on facebook is increasing, it is used for the self monitoring and public self consciousness [24]. When one searches the information on the internet then it is observed that children are sending illegal messages across network however these are restricted by various social networking websites but have reverse implications over the education [25]. When one visited on the facebook page then personality of individual can be easily accessed or checked but author observed that a lots of fraud information are also available on social networking websites [26].

Since hit ratio of social networking websites is more in comparison of other websites, therefore these websites are more popular to keep people no lonely. Today people are much busy on the social networking websites for mediating role of self-disclosure and social-support, cyber psychology behavior [27]. Registered users are large in numbers on facebook websites and users have created profile, personal profile, photo galleries and day to day uploading of messages. It creates self-esteem and people feel more satisfaction when they come across on facebook website [28]. Job seekers use the social websites or job websites for floating their profiles and to communicate with the employers. In this connection big five personality traits for job aspirants are well explained by Stoughton et al. [29].

In the present work, an object-oriented unified modeling language is used, therefore it is necessary to explain some of the important references related to the UML. It a graphical general purpose visual language for creation of model and all symbols and notations are well designed and explained by Object Management Group (OMG) [30,31]. From time to time, various models for the real time system, embedded system are proposed and validated by the researchers. It supports static and dynamic behavior of the research problem. In this work, a class and an activity models for people happiness are designed through Internet Addiction Test (IAT) and validated for finding the important observations in respect of Indian scenario. The popular modeling language was invented by well known scientist Booch et al. [32].

\section{Materials and Methods}

\section{Classification of data}

For classification of data, a sample size of 500 people is considered for Internet Addiction Test (IAT) after forming a questionnaire represented in Table 1. Before collection of data, ethical consent has been taken of individual through personnel visit to the houses of person located in the Lucknow city of India. The following major dependent classes are taken into account:

CLASS A $\rightarrow$ People feel loneliness (represented as LONELINESS class)

CLASS B $\rightarrow$ People get self-disclosure (represented as SELF_ DISCLOSURE class)

CLASS C $\rightarrow$ People get social-support (represented as SOCIAL_ SUPPORT class)

\section{CLASS D $\rightarrow$ People feel happiness (represented as HAPPINESS class)}

Let us describe interpretation of one class i.e. LONELINESS class. It consists of dependent attributes like loneliness_type, loneliness_in_ time, loneliness_out_time as shown in the Figure 1. In similar fashion, attributes are described in the remaining three major classes. In the LONELINESS class, two operations are considered namely listen_songs (), watch_video () which depend on attributes. In similar manner, other attributes are designed for three remaining classes. The questionnaire consists of 20 valuable questions and these are divided into above four major classes. The questions are scaled according to the following measures:

\section{$1=$ Rarely, $2=$ Occasionally, $3=$ Frequently, $4=$ Often, $5=$ Always}

The age of people is considered from $20-26$ years, $50 \%$ people were below 22 years with mean age of 22.35 years with standard deviation SD as 1.53 .

\section{UML model for minimization of loneliness of people}

Let us explain UML class model for conversion of loneliness of the people into happiness. It is represented in Figure 1 and person is considered as a user which is connected across the distributed computing network. The diagram is based upon the six classes or objects which are interacting in such a way that multiple users (represented as ${ }^{*}$ ) controlled by USER class and user may have multiple types of internet connection (controlled by INTERNET class). The association between two classes is represented by a relationship written on the link, for example a statement like User feels Loneliness; it is represented at the top of figure controlled by two classes namely USER and LONELINESS; feels is written on top of line joining these two classes; ${ }^{*}$ shows the kind of multiple relationship which means that many Users feel Loneliness at multiple times.

The other classes are designed as SELF_DISCLOSURE, SOCIAL_ SUPPORT and HAPPINESS. Users disclose their identity on the internet and get social-support controlled by SOCIAL_SUPPORT class. When User becomes Happy after self-disclosing and getting the social- 


\begin{tabular}{|c|c|c|}
\hline $\begin{array}{l}\text { Name of } \\
\text { Class }\end{array}$ & $\begin{array}{l}\text { Data } \\
\text { Items }\end{array}$ & Description of Data Itemt \\
\hline \multirow{6}{*}{ CLASS A } & Item A1 & $\begin{array}{l}\text { How often do you feel uneasy when away from the } \\
\text { internet? }\end{array}$ \\
\hline & Item A2 & How often do you feel that internet is boring? \\
\hline & Item A3 & How often you go online after disconnection from internet? \\
\hline & ItemA4 & How often you planned to away from internet? \\
\hline & Item A5 & How often you feel uneasy due to last night wake up? \\
\hline & Item A6 & $\begin{array}{l}\text { How often you feel that your life is nothing without } \\
\text { internet? }\end{array}$ \\
\hline \multirow{5}{*}{ CLASS B } & Item B1 & $\begin{array}{l}\text { How often are you afraid of sharing personal information } \\
\text { on internet? }\end{array}$ \\
\hline & Item B2 & $\begin{array}{l}\text { How often do you feel that internet is trust worthy than } \\
\text { friends? }\end{array}$ \\
\hline & Item B3 & $\begin{array}{l}\text { How often you check first your email account than visiting } \\
\text { the other websites? }\end{array}$ \\
\hline & Item B4 & $\begin{array}{l}\text { How often do you share all personal details on social } \\
\text { networking websites? }\end{array}$ \\
\hline & Item B5 & $\begin{array}{l}\text { How often do you pay online for purchase through } \\
\text { internet? }\end{array}$ \\
\hline \multirow{4}{*}{ CLASS C } & Item C1 & $\begin{array}{l}\text { How often do you get solution of all the problems on } \\
\text { internet? }\end{array}$ \\
\hline & Item C2 & $\begin{array}{l}\text { How often do you find that internet gives right tutorials, } \\
\text { lectures and right information rather than other mode? }\end{array}$ \\
\hline & Item C3 & $\begin{array}{c}\text { How often do you quarrel with your family members when } \\
\text { you act over internet? }\end{array}$ \\
\hline & Item C4 & $\begin{array}{l}\text { How often do you feel that online friends are more } \\
\text { reliable? }\end{array}$ \\
\hline \multirow{5}{*}{ CLASS D } & Item D1 & $\begin{array}{l}\text { How often you missed your meals due to spending more } \\
\text { time on internet? }\end{array}$ \\
\hline & Item D2 & $\begin{array}{l}\text { How often do you prefer to shop online rather than going } \\
\text { to market? }\end{array}$ \\
\hline & Item D3 & $\begin{array}{l}\text { How often do you feel that internet is necessary rather } \\
\text { than family members? }\end{array}$ \\
\hline & Item D4 & $\begin{array}{l}\text { How often do you enjoy internet seeing through online } \\
\text { adult movie? }\end{array}$ \\
\hline & Item D5 & How often you prefer to be online every time? \\
\hline
\end{tabular}

Table 1: Categorization of Classes According to data items

support, then it is controlled by HAPPINESS class. In the diagram, each class has its own attributes and the operations which can interact through the objects.

Let us explain UML activity diagram. The different activities for internet addiction are arranged in such a way that how people becomes addicted to internet to minimize loneliness through social networking websites.t shows the pictorial representation in form of activities. The first activity is related to that people feel loneliness and for minimizing loneliness the people take the internet connection through the service provider. After getting the connection, people surf the different social networking websites and create account by disclosing their personal information. It is also observed from different social networking websites like www.facebook.com, people put wrong information for creating the account and it covers under cyber crime laws. After selfdisclosure, people get response from different other users who can share the information thereafter, people enjoys the social networking websites and feel happiness. From the diagram it is clear that accessing of social networking websites plays a mediating role between loneliness and happiness.

\section{Formulation of hypothesis}

After defining the UML class and activity diagrams for minimization of loneliness into happiness, one can easily formulate the following hypothesis:

H1: Loneliness decreases happiness: From the UML activity diagram, it is clear that if users do not have internet connection and not accessing the social networking websites then people feel more loneliness and it decreases the parameter of happiness.

H2: Self-disclosure increases happiness: If users disclose the identity on the social networking websites then users feel happiness and it is directly related to increasing the happiness duration because it gives self-satisfaction to the user.

H3: Social-support increases happiness: According to the UML activity diagram, if users get social-support then it is directly related to the happiness. Social-support increases the count of the numbers of the friends on the social networking websites and day by day the friend list of the users is updating which gives the happiness to the users in such a way that the users may communicate or share information to the larger group.

\section{Validation of UML activity model}

Now, let us validate UML activity model by the use of concepts of Finite State Machine (FSM). In FSM, a machine is defined by

$$
\mathrm{M}=\left(\mathrm{Q}, \Sigma, \delta, \mathrm{q}_{0}, \mathrm{~F}\right)
$$

where, $\mathrm{Q}, \Sigma \delta, \mathrm{q}_{0}, \mathrm{~F}$ denote as a finite set of state, a finite set of input symbols, a transition function, an initial state of $Q$ and a set of the final or accepting state, respectively. The set of $\mathrm{F}$ is a subset of $\mathrm{Q}$.

By the use of above definition, a finite state machine is constructed whose states are corresponding to the variable Q. All the input symbols and transition in the system are corresponding to the variables $\Sigma$ and $\delta$, respectively. Let us describe the various activities from UML activity diagram which are represented in Table 2 . These activities are represented in the state transition diagram as shown in Figure 3. The two activities are connected through an event represented as a,b,c,d,e,f,g,h and i. For example, two activities namely $\mathrm{q}_{0}$ and $\mathrm{q}_{1}$ are connected through event a. The various events are described in Table 3. In such a manner, UML activity diagram is converted into a finite state machine as shown in Figure 3. For validation of UML activity diagram, one can generate the different test cases from the following grammar derived from state transition diagram.

$$
\begin{array}{lll}
\delta\left(\mathrm{q}_{0}, \mathrm{a}\right)=\mathrm{q}_{1} & \Rightarrow & \mathrm{q}_{0} \rightarrow \mathrm{aq}_{1} \\
\delta\left(\mathrm{q}_{1}, \mathrm{~b}\right)=\mathrm{q}_{0} & \Rightarrow & \mathrm{q}_{1} \rightarrow \mathrm{bq}_{0} \\
\delta\left(\mathrm{q}_{1}, \mathrm{c}\right)=\mathrm{q}_{2} & \Rightarrow & \mathrm{q}_{1} \rightarrow \mathrm{cq}_{2} \\
\delta\left(\mathrm{q}_{2}, \mathrm{~d}\right)=\mathrm{q}_{3} & \Rightarrow & \mathrm{q}_{2} \rightarrow \mathrm{dq}_{3} \\
\delta\left(\mathrm{q}_{3}, \mathrm{e}\right)=\mathrm{q}_{4} & \Rightarrow & \mathrm{q}_{3} \rightarrow \mathrm{eq}_{4} \\
\delta\left(\mathrm{q}_{0}, \mathrm{f}\right)=\mathrm{q}_{4} & \Rightarrow & \mathrm{q}_{0} \rightarrow \mathrm{fq}_{4} \\
\delta\left(\mathrm{q}_{4}, \mathrm{~g}\right)=\mathrm{q}_{5} & \Rightarrow & \mathrm{q}_{4} \rightarrow \mathrm{gq}_{5} \\
\delta\left(\mathrm{q}_{5}, \mathrm{~h}\right)=\mathrm{q}_{6} & \Rightarrow & \mathrm{q}_{5} \rightarrow \mathrm{hq}_{6} \\
\delta\left(\mathrm{q}_{4}, \mathrm{i}\right)=\mathrm{q}_{6} & \Rightarrow & \mathrm{q}_{4} \rightarrow \mathrm{iq}_{6} \\
\delta\left(\mathrm{q}_{0}, \mathrm{j}\right)=\mathrm{q}_{6} & \Rightarrow & \mathrm{q}_{0} \rightarrow \mathrm{jq}_{6}
\end{array}
$$

From the above grammar the events are organized into a transition 
Citation: Zaidi T, Saxena V (2015) Modeling for Minimization of Loneliness of People on the Social Networking Websites. J Psychiatry 18: 257 doi: 10.4172/2378-5756.1000257

Page 4 of 7

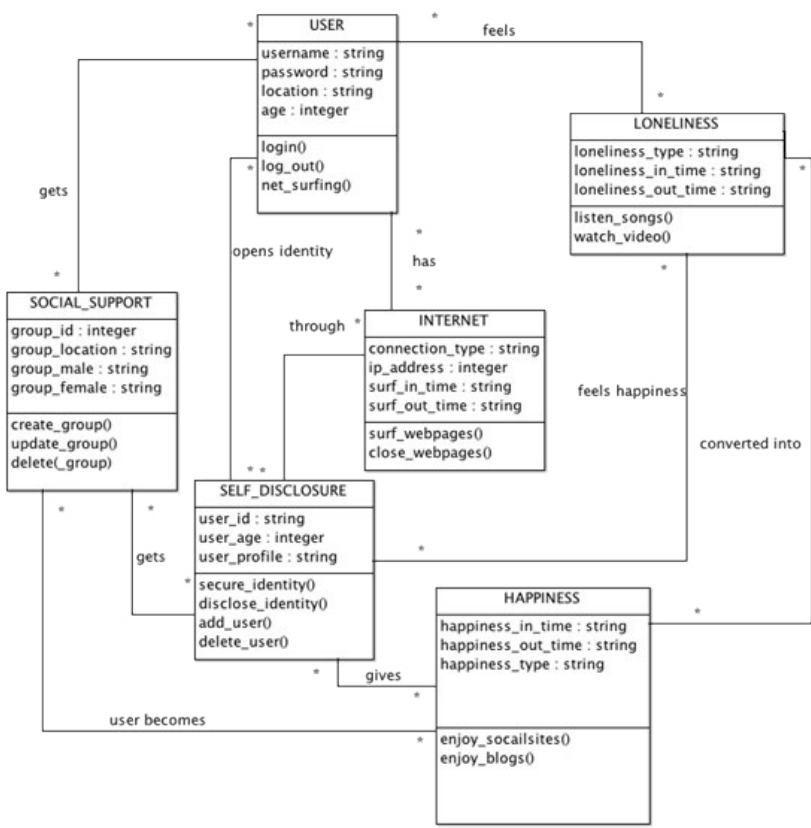

Figure 1: Uml Class Model for Conversion of Loneliness into Happiness.

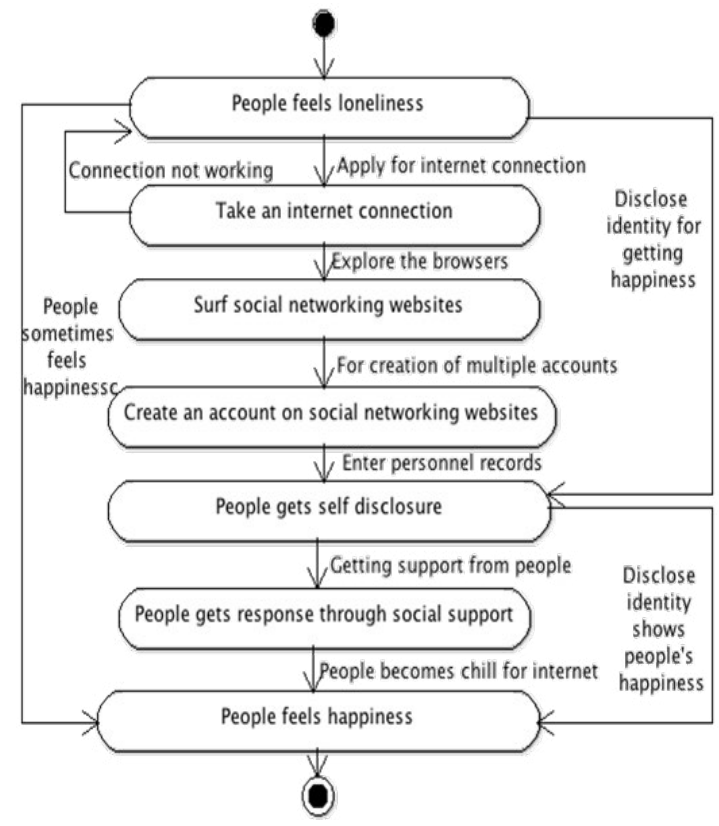

Figure 2: Uml Activity Model for Conversion of Loneliness into Happiness

table represented in Table 4. A symbol $\phi$ is considered as a null. From the table, different test cases are generated for validation of UML activity model and described below in brief:

Valid Test Case 1: People feel loneliness: For this case the equivalent grammar is generated below:

$$
\begin{aligned}
& \text { q0 } \rightarrow \text { aq1 } \\
& \text { q1 } \rightarrow \text { b }
\end{aligned}
$$

\section{Name of Activity}

People feel loneliness

Take an internet connection

Surf social networking websites

Create an account on social networking

websites

People get self disclosure

People get response through social

support

People feel happiness

Table 2: Representation of Activities from Uml Activity Diagram

\begin{tabular}{|l|l|}
\hline Event Description & Representation of Event \\
\hline Apply for internet connection & a \\
\hline Explore the browsers & b \\
\hline Connection not working & c \\
\hline For creation of multiple accounts & d \\
\hline Enter personal records & e \\
\hline Disclose the identity for getting happiness & f \\
\hline Getting support from people & g \\
\hline People becomes chill & h \\
\hline People sometimes feel happiness & i \\
\hline Disclosure identity shows peoples' happiness & j \\
\hline
\end{tabular}

Table 3: Representation of Events from Uml Activity Diagram

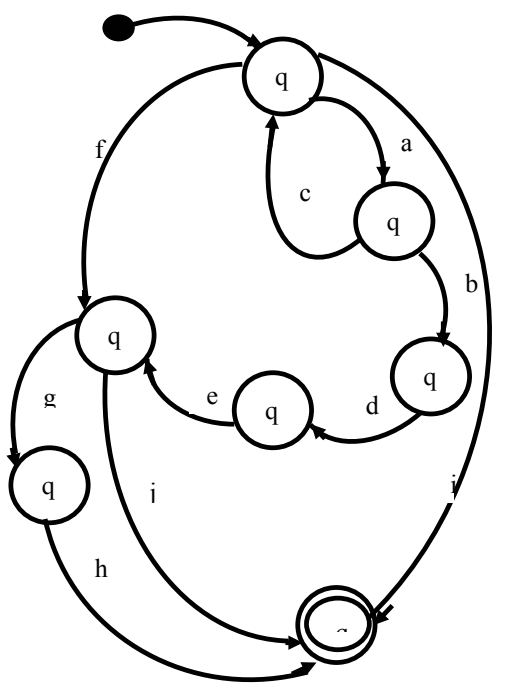

Figure 3: State Transition Diagram of Uml Activities

By replacing the non-terminals on right hand side, the string "ab" shows that when internet connection is not working then people feel loneliness.

Valid Test Case 2: People get social-support and feel happiness: In this case, the equivalent grammar is generated below:

$$
\begin{aligned}
& \mathrm{q} 4 \rightarrow_{\mathrm{gq} 5} \\
& \mathrm{q} 5 \rightarrow_{\mathrm{hq} 6} \rightarrow_{\mathrm{h}}
\end{aligned}
$$

By replacing the non-terminals on right hand side, the string "gh" shows that the people gets social-support through surfing the social networking web pages then they feel happiness.

Test case 3: People sometimes feel happiness: This test case covers 


\begin{tabular}{|c|c|c|c|c|c|c|c|c|c|c|}
\hline$\delta / \Sigma$ & $\mathbf{a}$ & b & c & d & e & $f$ & $\mathbf{g}$ & $\mathbf{h}$ & $\mathbf{i}$ & $\mathbf{j}$ \\
\hline $\mathrm{q}_{0}$ & $\mathrm{q}_{1}$ & $\varphi$ & $\varphi$ & $\varphi$ & $\varphi$ & $\mathrm{q}_{4}$ & $\varphi$ & $\varphi$ & $\varphi$ & $\varphi$ \\
\hline $\mathrm{q}_{1}$ & $\varphi$ & $\mathrm{q}_{0}$ & $\mathrm{q}_{2}$ & $\varphi$ & $\varphi$ & $\varphi$ & $\varphi$ & $\varphi$ & $\varphi$ & $\varphi$ \\
\hline $\mathrm{q}_{2}$ & $\varphi$ & $\varphi$ & $\varphi$ & $q_{3}$ & $\mathrm{q}_{4}$ & $\varphi$ & $\varphi$ & $\varphi$ & $\varphi$ & $\varphi$ \\
\hline $\mathrm{q}_{3}$ & $\varphi$ & $\varphi$ & $\varphi$ & $\varphi$ & $\mathrm{q}_{4}$ & $\varphi$ & $\varphi$ & $\varphi$ & $\varphi$ & $\varphi$ \\
\hline $\mathrm{q}_{4}$ & $\varphi$ & $\varphi$ & $\varphi$ & $\varphi$ & $\varphi$ & $\varphi$ & $q_{5}$ & $\varphi$ & $\mathrm{q}_{6}$ & $\varphi$ \\
\hline $\mathrm{q}_{5}$ & $\varphi$ & $\varphi$ & $\varphi$ & $\varphi$ & $\varphi$ & $\varphi$ & $\varphi$ & $\mathrm{q}_{6}$ & $\varphi$ & $\varphi$ \\
\hline $\mathrm{q}_{6}$ & $\varphi$ & $\varphi$ & $\varphi$ & $\varphi$ & $\varphi$ & $\varphi$ & $\varphi$ & $\varphi$ & $\varphi$ & $\mathrm{q}_{0}$ \\
\hline
\end{tabular}

Table 4: A transition Table

\begin{tabular}{|c|c|c|c|c|c|c|c|c|c|c|c|}
\hline $\begin{array}{l}\text { Name of } \\
\text { Class }\end{array}$ & $\begin{array}{l}\text { Data } \\
\text { Items }\end{array}$ & $\begin{array}{l}\text { Rarely } \\
\text { (1) }\end{array}$ & $\begin{array}{c}\text { Occasionally } \\
(2)\end{array}$ & $\begin{array}{l}\text { Frequent } \\
\text { (3) }\end{array}$ & Often (4) & $\begin{array}{c}\text { Always } \\
\text { (5) }\end{array}$ & Item Mean & Factor Loadings & $\begin{array}{l}\text { Composite } \\
\text { Reliability }\end{array}$ & $\begin{array}{l}\text { Variance } \\
\text { Extracted }\end{array}$ & $\begin{array}{c}\text { Cronbach's } \\
\text { Alpha }\end{array}$ \\
\hline \multirow{6}{*}{ CLASS A } & Item A1 & 40 & 150 & 90 & 120 & 100 & 3.18 & 0.80 & \multirow{6}{*}{0.912} & \multirow{6}{*}{0.79} & 0.956 \\
\hline & Item A2 & 100 & 120 & 110 & 80 & 90 & 2.88 & 0.55 & & & \\
\hline & Item A3 & 160 & 90 & 60 & 70 & 120 & 2.8 & 0.91 & & & \\
\hline & ItemA4 & 110 & 170 & 80 & 40 & 100 & 2.7 & 0.70 & & & \\
\hline & Item A5 & 100 & 170 & 80 & 40 & 110 & 2.78 & 0.85 & & & \\
\hline & Item A6 & 100 & 110 & 90 & 100 & 100 & 2.99 & 0.92 & & & \\
\hline \multirow{5}{*}{ CLASS B } & Item B1 & 130 & 100 & 100 & 70 & 100 & 2.82 & 0.72 & \multirow{5}{*}{0.836} & \multirow{5}{*}{0.64} & 0.925 \\
\hline & Item B2 & 130 & 130 & 60 & 120 & 60 & 2.7 & 0.65 & & & \\
\hline & Item B3 & 130 & 100 & 130 & 40 & 100 & 2.76 & 0.71 & & & \\
\hline & Item B4 & 160 & 140 & 120 & 60 & 20 & 2.28 & 0.72 & & & \\
\hline & Item B5 & 120 & 150 & 80 & 110 & 40 & 2.6 & 0.75 & & & \\
\hline \multirow{4}{*}{ CLASS C } & Item C1 & 100 & 30 & 150 & 80 & 140 & 3.28 & 0.86 & \multirow{4}{*}{0.899} & \multirow{4}{*}{0.67} & 0.896 \\
\hline & Item C2 & 60 & 100 & 90 & 110 & 140 & 3.34 & 0.79 & & & \\
\hline & Item C3 & 110 & 80 & 120 & 80 & 110 & 3.0 & 0.85 & & & \\
\hline & Item C4 & 100 & 110 & 60 & 90 & 140 & 3.12 & 0.82 & & & \\
\hline \multirow{5}{*}{ CLASS D } & Item D1 & 80 & 20 & 40 & 180 & 180 & 3.72 & 0.85 & \multirow{5}{*}{0.933} & \multirow{5}{*}{0.68} & 0.835 \\
\hline & Item D2 & 110 & 200 & 50 & 110 & 30 & 3.32 & 0.79 & & & \\
\hline & Item D3 & 100 & 40 & 60 & 110 & 190 & 3.50 & 0.88 & & & \\
\hline & Item D4 & 70 & 70 & 90 & 110 & 160 & 3.54 & 0.82 & & & \\
\hline & Item D5 & 100 & 30 & 140 & 60 & 170 & 3.34 & 0.94 & & & \\
\hline
\end{tabular}

Table 5: Test for Convergence of Results

the following grammar

$$
\begin{aligned}
& \mathrm{q} 0 \rightarrow \mathrm{jq}_{6} \\
& \mathrm{q}_{6} \rightarrow \phi
\end{aligned}
$$

By replacing the non-terminals on right hand side, the string " $\mathrm{j}$ " is the event from $\mathrm{q}_{0}$ to $\mathrm{q}_{6}$ which shows that the people sometimes feel happiness.

\section{Results}

A sample size of 500 is considered for classifying the data items as recorded in the Table 1 and five points scale is used for obtaining the observations that how people became happiness from the loneliness. Table 5 shows the convergence of results according to structure equation modeling. Five point scale ranging from $1=$ "rarely agreed" to $5=$ "always agree" is used to obtain the composite reliability and extracted variance for convergence validity of obtained results. All factors loading are more than 0.5. For class A composite reliability is 0.912 and according to "rule of thumb", it should be greater than 0.70 and shows that loneliness occurs among the group of people. According to the designed UML model which shows the steps for conversion of loneliness into happiness and for class $\mathrm{D}$, composite reliability is 0.933 which represents high degree of composite reliability. Extracted average variance is also computed and in all the cases, it is more than 0.6. It is observed that the average variance extracted more than 0.6 demonstrates the convergence validity of obtained results depicted in the Table 5. All squared correlations are less than the average variance extracted.

\section{Discussion}

In the present study, author used three types of hypothesis. In the first hypothesis $\mathrm{H} 1$ which shows that loneliness decreases the happiness. The proposed classes are dependent to each other. The class A shows that people feel happiness, the composite reliability is computed as 0.912 which is more than 0.70 . It shows that reliability is acceptable. Cronbach's Alpha is computed as 0.956 which is more than acceptable composite reliability which represents the internal consistency of the proposed data items. From the UML activity diagram Figure 2, loneliness is directly related to the happiness, the two classes A and $\mathrm{D}$ are mutually dependent. The composite reliability of class A show that high degree of loneliness occurs in the group of the people but when it is linked to class $\mathrm{D}$ then composite reliability increases i.e. 0.933 and it is again more than 0.70 which is acceptable. It represents that the assumption $\mathrm{H}_{1}$ is true since loneliness decreases happiness. It is also obvious from computed Alphas i.e. 0.835 and greater than the composite reliability.

The second assumption $\mathrm{H}_{2}$ shows that the self disclosure increases happiness. It is controlled by class $\mathrm{B}$ and composite reliability is computed as 0.836 . From the UMl activity diagram Class B is linked 
to the Class $\mathrm{D}$ which shows that self-disclosure is directly related to the happiness. For class $\mathrm{B}$, the composite reliability is computed as 0.836 which is again more than 0.70 and it is acceptable. It is linked to the class $\mathrm{D}$ and composite reliability is further increases i.e. 0.933 which represents high degree of acceptance of the data items. Cronbach's Alpha is computed as 0.896 and it is decreases for the class D. It represents that when person do self-disclosure then it produces high degree of the happiness.

The last assumption $\mathrm{H}_{3}$ represents that social-support is directly related to the happiness. From the UML activity diagram, class $\mathrm{C}$ controls social-support and it is linked to the class D. For the class C, the composite reliability is computed as 0.899 which is further greater than 0.70 . It is acceptable and represents high degree of social-support. Further, it is linked to the class D, the composite reliability increases as 0.933 which is acceptable. It shows that social-support increase the happiness.

\section{Conclusions}

From the above work it is concluded that the presented modeling approach is suitable for the solution of the complex research problems. In the work object-oriented modeling approach is used to minimize the loneliness of the people and converted into the happiness by considering mediating role of self-disclosure and social-support. Different variables are considered after defining the four major classes. It is observed that the loneliness is directly related to the happiness of people. From the proposed activity model, it is found that the people who remain lonely feel minimum happiness. But getting the self-disclosure and socialsupport, it is converted into the happiness and class $\mathrm{D}$ has composite reliability 0.933 and average variance extracted is 0.68 which represent towards convergent validity of the observed data. Due to evolution of internet, the people may enjoy the services of the internet by using the different devices having heterogeneous specifications well connected across the distributed network. They feel lonely when internet services are temporarily not working, therefore, previous studies reveal that the people feel lonelier when internet services were not available but in current study it is observed that social-support through social networking websites, loneliness can be easily minimized and converted into happiness. The presented work is confined towards the study in the Indian scenario which can be further extended for the other countries.

In the presented model, object-oriented approach is followed and model is platform independent and one can easily develop the software code for minimization of the loneliness into the happiness by taking various kinds of attributes as mentioned in the study. The presented data are tested and results are found convergent. For future study, linear regression technique shall be helpful for different age group of the people.

\section{Acknowledgements}

Author is very thankful to the University Grants Commission, New Delhi, India and Ministry of Human Resource and Development for supporting to the Thapar University, Patiala.

\section{References}

1. Hwang K (2007) Advanced computer architecture: parallelism, scalability, programmability, Fourteen Reprint, Tata McGraw Hill Edition, ISBN-0-07, 053070 .

2. Milenkovic M (1987) Operating systems: concepts and design, Tata McGraw Hill 1987.

3. Bargh JA, McKenna KYA (2004) The Internet and social life. Annual Review of Psychology 55: 573-90
4. Valenzuela, Park N, Kee KF (2009) Is there social capital in a social network site?: Facebook use and college students' life satisfaction, trust, and participation. Journal of Computer-Mediated Communication, 14: 875-901.

5. Boyd DM, Ellison NB (2007) Social network sites: definition, history, and scholarship. Journal of Computer-Mediated Communication 13: 210-30.

6. Nie NH (2001) Sociability, interpersonal relations, and the Internet: reconciling conflicting findings. American Behavioral Scientist 45: 420-35.

7. Liu X, LaRose R (2008) Does using the Internet make people more satisfied with their lives? The effects of the Internet on college students school life satisfaction. Journal of Cyber Psychology and Behavior 11: 310-20.

8. Shaw LH, Gant LM (2002) In defense of the Internet: the relationship between Internet communication and depression, loneliness, self-esteem, and perceived social support. Journal of Cyber Psychology and Behavior 5: 157-70.

9. Lee G, Lee J, Kwon S (2011) Use of social networking sites and subjective wellbeing: a study in South Korea. Cyber Psychology, Behavior, and Social Networking 14: 151-5.

10. Diener E, Lucas RE, Oishi S (2005) Subjective wellbeing: the science of happiness, and self-satisfaction. In Snyder CR, Lopez SJ, eds. Handbook of Positive Psychology. New York: Oxford University Press 63-73.

11. Ellison NB, Steinfield C, Lampe C (2007) The benefits of Facebook "friends' 'social capital, and college students' use of online social network sites. Journal of Computer Mediated Communication 12: 1143-68.

12. Kalpidou M, Costin D, Morris J (2011) The relationship between Facebook and the wellbeing of undergraduate college students. Journal of Cyber Psychology, Behavior, and Social Networking 14: 183-9.

13. Ceyhan A, Ceyhan E (2007) Loneliness, depression, and computer selfefficacy as predictors of problematic Internet use. Journal of Cyber Psychology and Behavior 11: 699-701.

14. Kim J, LaRose R, Peng W (2009) Loneliness as the cause and the effect of problematic Internet use: the relationship between Internet use and psychological wellbeing. Journal of Cyber Psychology and Behavior 12: 45-5.

15. Russell D (1996) The UCLA Loneliness scale: reliability, validity,

16. Amichai-Hamburger Y, Ben-Artzi E (2003) Loneliness and internet use. Journal of Computers in Human Behavior 19: 71-80

17. Gupta S, Kim HW, Shin SJ (2010) Converting virtual community members into online buyers. Journal of Cyber Psychology, Behavior and Social Networking 13: $513-20$.

18. Bessiere K, Kiesler S, Krant R (2008) Effects of Internet use and socia resources on changes in depression, information. Journal of Communication and Society 11: 47-70.

19. Clark LA, Roberts SJ (2010) Employer's use of social networking sites: a socially irresponsible practice. Journal of Business Ethics 95: 507-25.

20. Orchard LJ, Fullwood C (2010) Current perspectives on personality and Internet use. Social Science Computer Review 28: 155-69.

21. Wortham J (2009) More employers use social networks to check out applicants.

22. Barrick MR, Mount MK (1991) The Big Five personality dimensions and job performance: a meta-analysis. Journal of Personnel Psychology 44: 1-26.

23. Tosun LP, Lajunen T (2009) why do young adults develop a passion for Internet activities? The associations among personality, revealing "true self" on the Internet, and passion for the Internet. Journal of Cyber Psychology and Behavior 12: 401-6.

24. Gogolinski TB (2010) Effects of self-monitoring and public self-consciousness on perceptions of Facebook profiles. Colonial Academic Alliance Undergraduate Research Journal 1: 1-29.

25. Marcus B, Machilek F, Schütz A (2006) Personality in cyberspace: persona websites as media for personality expressions and impressions. Journal of Personality and Social Psychology 90: 1014-31.

26. Brown VR, Vaughn ED (2011) The writing on the (Facebook) wall: the use of social networking sites in hiring decisions. Journal of Business and Psychology 26: 219-25.

27. Lee KY, Noh MJ, Koo DM (2013) Lonely People Are No Longer Lonely on Social Networking Sites: The Mediating Role 
Citation: Zaidi T, Saxena V (2015) Modeling for Minimization of Loneliness of People on the Social Networking Websites. J Psychiatry 18: 257 doi: 10.4172/2378-5756.1000257

Page 7 of 7

28. Gonzales AL, Hancock JT (2011) Mirror, mirror on my Facebook wall: effects of exposure to Facebook on self-esteem. Journal of Cyber Psychology, Behavior and Social Networking 14:79-83.

29. Stoughton JW, Thompson MS, Lori F, Meade AW (2013) Big Five Personality Traits Reflected in Job Applicants' Social Media Postings. Journal of Cyber Psychology, Behavior and Social Networking 16.
30. OMG (2001) Unified Modeling Language Specification. Available online via.

31. OMG (2003) Unified Modeling Language (UML)-Version 1.5”, OMG document formal/2003-3-01, Needham MA.

32. Booch G, Rambaugh J, Jacobson I (1999) The Unified Modeling Language User Guide, Addison Wesley, Reading, MA 